\title{
Gender-Specific Modulation of the Response to Arterial Injury by Soluble Guanylate Cyclase $\alpha 1$
}

\author{
Pieter Vermeersch ${ }^{1}$, Emmanuel Buys ${ }^{4}$, Patrick Sips ${ }^{3}$, Peter Pokreisz ${ }^{1}$, Glenn Marsboom ${ }^{1}$, \\ Hilde Gillijns ${ }^{1}$, Marijke Pellens ${ }^{1}$, Mieke Dewerchin ${ }^{1}$, Kenneth D. Bloch ${ }^{4}$, Peter Brouckaert ${ }^{3}$, \\ and Stefan Janssens ${ }^{1,2, *}$
}

\author{
${ }^{I}$ Vesalius Research Center (VIB) and Cardiac Unit, ${ }^{2}$ University of Leuven, Leuven, Belgium, ${ }^{3}$ Department of Molecular \\ Biomedical Research (VIB), Ghent University, Ghent, Belgium and ${ }^{4}$ Cardiovascular Research Center, Harvard Medical \\ School, Charlestown, MA
}

\begin{abstract}
Objective: Soluble guanylate cyclase (sGC), a heterodimer composed of $\alpha$ and $\beta$ subunits, synthesizes cGMP in response to nitric oxide (NO). NO modulates vascular tone and structure but the relative contributions of cGMPdependent versus cGMP-independent mechanisms remain uncertain. We studied the response to vascular injury in male (M) and female (F) mice with targeted deletion of exon 6 of the sGC $\alpha 1$ subunit ( $\left(\mathrm{sCC} \alpha 1^{-\digamma^{-}}\right)$, resulting in a non-functional heterodimer.

Methods: We measured aortic cGMP levels and mRNA transcripts encoding sGC $\alpha 1$, $\alpha 2$, and $\beta 1$ subunits in wild type (WT) and $\mathrm{sGCa1}^{-/-}$mice. To study the response to vascular injury, BrdU-incorporation and neointima formation (maximum intima to media (I/M) ratio) were determined 5 and 28 days after carotid artery ligation, respectively.

Results: Aortic cGMP levels were 4-fold higher in $\mathrm{F}$ than in $\mathrm{M}$ mice in both genotypes, and, within each gender, 4-fold higher in WT than in $\mathrm{sGCa1}^{-/-}$. In contrast, $\mathrm{sGC} \alpha 1, \mathrm{sGC} \alpha 2$, and $\mathrm{sGC} \beta 1 \mathrm{mRNA}$ expression did not differ between groups. ${ }^{3} \mathrm{H}$-thymidine incorporation in cultured $\mathrm{sGCa}^{-/}$smooth muscle cells (SMC) was $27 \% \pm 12 \%$ lower than in WT SMC and BrdU-incorporation in carotid arteries 5 days after ligation was significantly less in $\mathrm{sGCa}^{-/-} \mathrm{M}$ than in WT M. Neointima area and I/M 28 days after ligation were $65 \%$ and $62 \%$ lower in $\mathrm{sGCa1}^{-/-} \mathrm{M}$ than in WT M mice $(p<0,05$ for both) but were not different in F mice.

Conclusion: Functional deletion of sGCa1 resulted in reduced cGMP levels in male sGCa1 ${ }^{-/-}$mice and a gender-specific effect on the adaptive response to vascular injury.
\end{abstract}

Key Words: Soluble guanylate cyclase, gender, vascular remodelling, nitric oxide.

\section{INTRODUCTION}

Nitric oxide (NO) plays an important role in maintaining normal vascular tone and modulates the function of vascular cells participating in the response to arterial injury. A better understanding of the molecular mechanisms regulating the response to vascular injury is fundamental to develop more effective therapies for atherosclerosis and restenosis following percutaneous vascular interventions. In the vessel wall, NO is produced by endothelial nitric oxide synthase (NOS3). The main intracellular receptor of $\mathrm{NO}$ is soluble guanylate cyclase (sGC), a heterodimer composed of $\alpha$ and $\beta$ subunits that catalyzes the conversion of GTP to cGMP in response to NO. A rise in cGMP can activate cGMP-dependent protein kinase 1 (cGKI) and result in vascular smooth muscle cell (SMC) relaxation. Recently, Mergia et al. reported that the targeted deletion of exon 4 of the sGC $\alpha 1$ subunit results in a greater than $90 \%$ reduction in aortic NO-stimulated sGC activity [1].

*Address correspondence to this author at the Vesalius Research Center, University of Leuven, 49, Herestraat, B-3000 Leuven, Belgium;

Tel: +32-16-345775; Fax: +32-16-345990;

E-mail: Stefan.janssens@med.kuleuven.ac.be
NO/cGMP signal transduction, one of the critical pathways modulating vascular function, is reduced in atherosclerosis [2] and after balloon injury [3]. Reduced NO bioavailability in the injured vessel wall is thought to contribute to the progression of vascular lesions and has spurred interest in various interventions aimed at augmenting local NO/cGMP signal transduction. Among these, adenovirusmediated overexpression of NOS3 [4] or both sGC subunits with administration of molsidomine, a NO-donor [5], inhibits SMC proliferation in vitro and neointima formation in vivo in rats, suggesting a vasoprotective effect of $\mathrm{NO} / \mathrm{cGMP}$ signaling. In line with these observations, $\mathrm{ApoE}^{-/-} \mathrm{NOS}^{-1-}$ mice have a larger neointima after femoral cuff placement [6] and carotid artery ligation [7] and show increased plaque development in an $\mathrm{ApoE}^{-/-}$background $[8,9]$ as compared to WT mice. However, transgenic mice overexpressing NOS3 in the vascular endothelium also show accelerated atherosclerosis [10], whereas mice with a SMC-specific deletion of cGKI (SMC-cGKI ${ }^{-1}$ ) develop less atherosclerosis [11]. These observations suggest that NO-mediated signal transduction can have variable effects on the response to vascular injury, which might be related to an altered balance between cGMP-dependent signaling and cGMP-independent mechanisms including S-nitrosylation of proteins and the generation of reactive oxygen species [12]. 
The role of cGMP in modulating the response to vascular injury has not been systematically studied. We, therefore, investigated the effect of reduced endogenous $\mathrm{NO} / \mathrm{cGMP}$ signal transduction on the response to vascular injury in male (M) and female (F) mice with a targeted deletion of exon 6 of $\mathrm{sGC} \alpha 1\left(\mathrm{sGC}^{-1-} 1^{-}\right)$. This deletion results in a nonfunctional $\alpha 1 \beta 1$ heterodimer and is associated with systemic hypertension in male but not female sGC $\alpha 1^{-1-}$ mice [13]. We observed gender- and genotype-specific alterations in aortic cGMP levels, corresponding to the impaired neointimal response to carotid injury in male $\mathrm{sGC}^{-1^{--}}$mice. Intact sGC gene function critically determines a gender-specific adaptive response to vascular injury.

\section{METHODS}

\section{Experimental Animals}

$\mathrm{sGC}^{-1 /} \mathrm{1}^{-1}$ mice with a targeted deletion of exon 6 of the $\alpha 1$ subunit gene were generated as described previously [13]. Experiments were performed in adult male and female sGC $\alpha 1^{-1-}$ (12 to 14 weeks old) and WT mice (10 to 16 weeks old) bread in a mixed genetic background (50\% Swiss $/ 50 \%$ $129 \mathrm{~Sv})$. The experiments conformed with the Guide for the Care and Use of Laboratory Animals published by the US National Institutes of Health (NIH Publication No. 85-23, revised 1996) and were approved by the Institutional Committee on Animal Care and Welfare of the University of Leuven (Belgium). A schematic representation explaining the timeline of the experiments is shown in Fig. (1).

\section{Vascular cGMP Concentrations}

The aorta was made bloodfree and immediately frozen in liquid nitrogen and kept at $-80^{\circ} \mathrm{C}$ until vascular cGMP concentrations were determined using a non-radioactive enzyme immunoassay according to the manufacturer's instructions (Amersham Biosciences, Little Chalfont, United Kingdom). Protein concentrations were determined with the BCA Protein assay kit (Pierce, Rockford, IL) and results expressed as pmol cGMP/mg protein.

\section{sGC Subunit mRNA Expression}

Assessment of mRNA transcript levels of murine sGC $\alpha 1$ (exon 5), sGC $\alpha 2$, sGC $\beta 1$, and hypoxanthine-guanine phosphoribosyl-transferase (HPRT) was performed by real-time fluorescence detection using specific primer sets, recognizing the respective murine DNA sequences (see reference
[14] for primer and probe sequences). Samples were run in triplicate together with a dilution series of a plasmid standard for each gene to allow comparison of the copy numbers of the different subunits. Results were expressed as copy numbers normalized to mHPRT.

\section{In Vitro SMC Proliferation and Migration}

Experiments were performed in early passage aortic

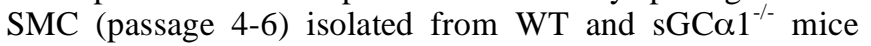
and cultured in DMEM $+10 \%$ fetal bovine serum. DNA synthesis and migration in response to serum stimulation were assessed using ${ }^{3} \mathrm{H}$-thymidine incorporation and Transwell migration chambers (Corning, Corning, NY), respectively. Results obtained with sGCa1-/- cells were expressed relative to WT cells and represent the mean of 6 independent experiments.

\section{Carotid Artery Ligation}

Animals were anesthetized with pentobarbital $(65 \mathrm{mg} / \mathrm{kg}$ IP) and the common carotid artery was ligated close to the bifurcation as described previously [15]. Animals were euthanized 28 days after ligation to determine neointima formation. To evaluate vascular cell turnover in vivo, 5'bromo-deoxyuridine (BrdU, $50 \mathrm{mg} / \mathrm{kg} \mathrm{IP}$ ) was injected in a separate group of animals 12 hours and 1 hour before euthanasia at 5 days when SMC turnover is maximal in the carotid artery ligation model [15]. Arteries were fixed in situ with $4 \%$ formaldehyde, embedded in paraffin, and 5- $\mu \mathrm{m}$ sections were prepared from the bifurcation towards the aortic arch. The reference point was set at the first section containing an intact internal and external elastic lamina.

\section{Histological Analysis of Injured Carotid Arteries}

To quantitate neointima formation, sections were stained at $50 \mu \mathrm{m}$ intervals with hematoxylin and eosin and analyzed by a blinded observer. Neointima area, media area, and internal elastic lamina (IEL) length were quantified using the KS300 morphometric analysis software (Zeiss, Oberkochen, Germany). The maximum intima to media (I/M) ratio (+50 to $+500 \mu \mathrm{m}$ from the reference point in all animals) and the corresponding neointima area, media area, and IEL length were reported. BrdU-positive cells in the media were detected using a monoclonal rat anti-BrdU antibody (Oxford Biotechnology, Kidlington, UK) as described previously [14] and expressed relative to the total cell number. In addition,

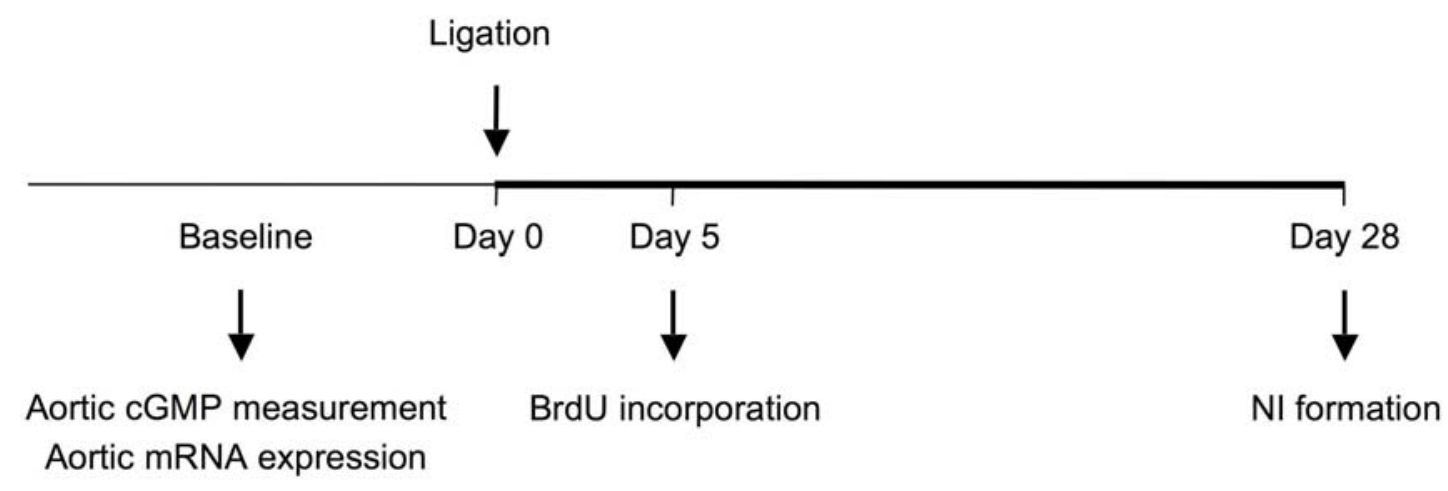

Fig. (1). Schematic representation explaining the timeline of the experiments. 
cellular composition in neointimal and medial areas 28 days after ligation was investigated using antibodies directed against $\alpha$-smooth muscle actin (SMC actin) (Dako, Glostrup, Denmark) and CD45 (Becton Dickinson, Franklin Lakes, NJ), a common leucocyte antigen. Additional stainings without primary antibody were included to control for nonspecific staining by secondary antibodies. Finally, the media area and IEL length of the contralateral carotid artery was quantitated to compare the response to increased flow in WT and sGCa1-/- mice.

\section{Statistics}

All values are expressed as mean \pm SD. A Student t-test was used to compare differences between 2 groups and one-way ANOVA to compare multiple groups. Posthoc analysis was performed using the Student-NewmanKeuls test or a Bonferroni correction (if variances were significantly different).

An expanded materials and methods section is available as online data supplement.

\section{RESULTS}

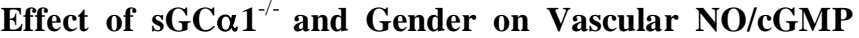 Signaling}

To investigate the effect of a truncated non-functional sGC $\alpha 1 \beta 1$ heterodimer on sGC mRNA expression, quantitative PCR (qPCR) was performed. Relative mRNA transcript levels of the sGC. subunits were comparable between the four groups (Table 1).

To investigate gender and genotype-dependent effects on sGC gene function, unstimulated aortic cGMP levels were measured. cGMP levels were 4-fold higher in females than in males in both genotypes ( $p<0.05$ each), and, within each gender, 4-fold higher in WT than in ${\mathrm{sGC} \alpha 1^{-/}}^{-1}(p<0.05$ each, Fig. 2).

\section{In Vitro SMC Proliferation and Migration}

To evaluate the effect of sGC gene function on SMC proliferation, DNA turnover was quantified by measuring ${ }^{3} \mathrm{H}$-thymidine incorporation in early passage SMC from sGCa $1^{-1-}$ and WT aortic explants. Proliferation was $27 \% \pm 12 \%$ lower in ${\mathrm{sGC} \alpha 1^{-/}}^{-}$than in WT cells $(\mathrm{n}=6, p<0.05)$. In contrast, vascular cell migration was comparable in cells from both genotypes $(97 \% \pm 24 \%, \mathrm{n}=6, p=\mathrm{ns})$. There was no difference between cells derived from male and female mice.

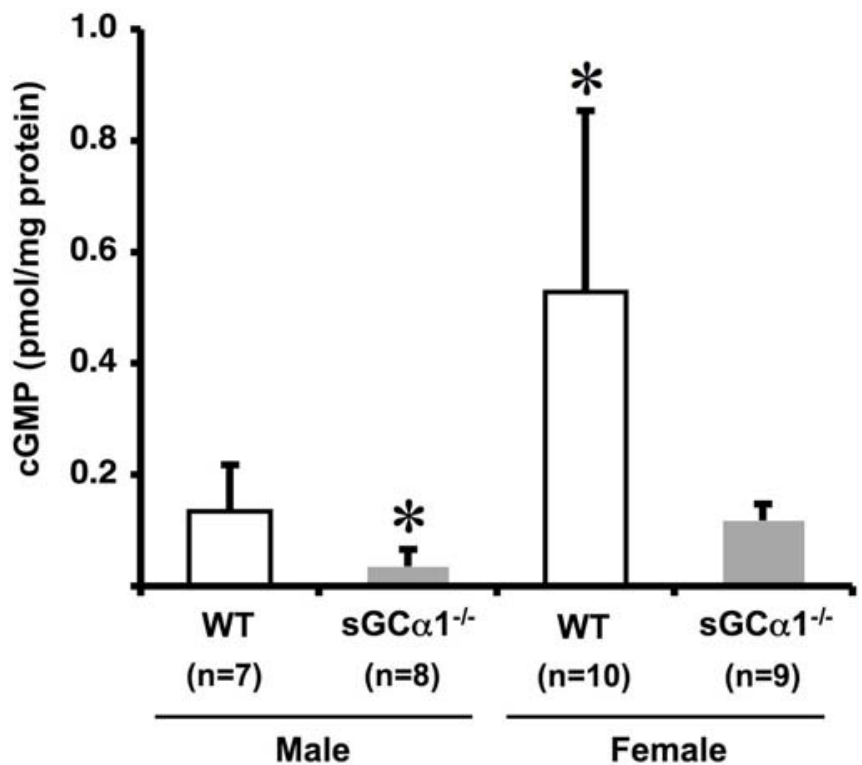

Fig. (2). Vascular cGMP levels in WT (open bars) and $s G C \alpha 1^{-1-}$ (closed bars) male mice (M) and female mice (F). Aortic cGMP levels were 4-fold higher in $\mathrm{F}$ than in $\mathrm{M}$ mice in either genotype, and, within each gender, 4 -fold higher in WT than in $\mathrm{sGC} \alpha 1^{-/-}$mice $(* p<0.05$ vs. all $)$.

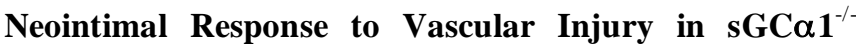 Mice}

To evaluate the role of sGC gene function in the adaptive response to vascular injury, the common carotid artery was surgically ligated in $\mathrm{WT}$ and $\mathrm{sGC} \alpha 1^{-/-}$mice. The maximum $\mathrm{I} / \mathrm{M}$ ratio in both genotypes was observed at a distance ranging from +50 to $+500 \mu \mathrm{m}$ proximal to the ligation, while almost no neointima was observed beyond $+1000 \mu \mathrm{m}$. Maximum I/M ratio 28 days after ligation was lower in $\mathrm{sGC} \alpha 1^{-1-} \mathrm{M}$ than in WT M mice ( $p<0.05$, Figs. $\mathbf{3 A}$ and $\mathbf{3 B}$, respectively) but was not different in $\mathrm{F}$ mice (Fig. 4A). Neointima area was also lower in $\mathrm{sGC} \alpha 1^{-1-} \mathrm{M}$ compared to WT M or F mice of either genotype ( $p<0.05$ vs. all). Media area and IEL length did not differ between groups (Table $\mathbf{2}$ ). The neointimal cells 4 weeks after ligation showed marked SMC actin immunoreactivity (Fig. 3C), while almost no CD45-positive inflammatory cells were observed in the neointima or the media (Fig. 3D). CD45 immunoreactivity was predominantly observed in the adventitia.

Table 1. Aortic mRNA Transcript Levels Normalized to HPRT

\begin{tabular}{|c|c|c|c|}
\hline WT M $(n=7)$ & $11.8 \pm 7.0$ & $1.5 \pm 0.3$ & $25.4 \pm 7.3$ \\
\hline WT F (n=6) & $13.1 \pm 3.9$ & $1.7 \pm 0.5$ & $18.3 \pm 2.7$ \\
\hline
\end{tabular}


We next investigated whether carotid artery ligation would differentially alter the response to increased flow in the contralateral carotid artery in both genotypes. There was no difference in media area or IEL length of the contralateral carotid artery in M or F mice (Table 2 ).

\section{BrdU-Incorporation 5 Days After Ligation}

To investigate genotype-associated changes in SMC turnover following vascular injury, BrdU was injected 12 hours and 1 hour before sacrifice in $\mathrm{WT}$ and $\mathrm{sGC} \alpha 1^{-1-}$ mice.
The proliferative index, expressed as $\%$ BrdU positive cells, was lower in $\mathrm{sGC} \alpha 1^{-1-} \mathrm{M}$ compared to WT M mice $(p<0.05$, Fig. 4B), which contributed to a reduced I/M ratio 28 days

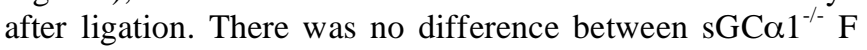
and WT F mice.

\section{DISCUSSION}

NO/cGMP signal transduction plays an important role in maintaining normal vascular function and structure and modulates the response to arterial injury. In the present

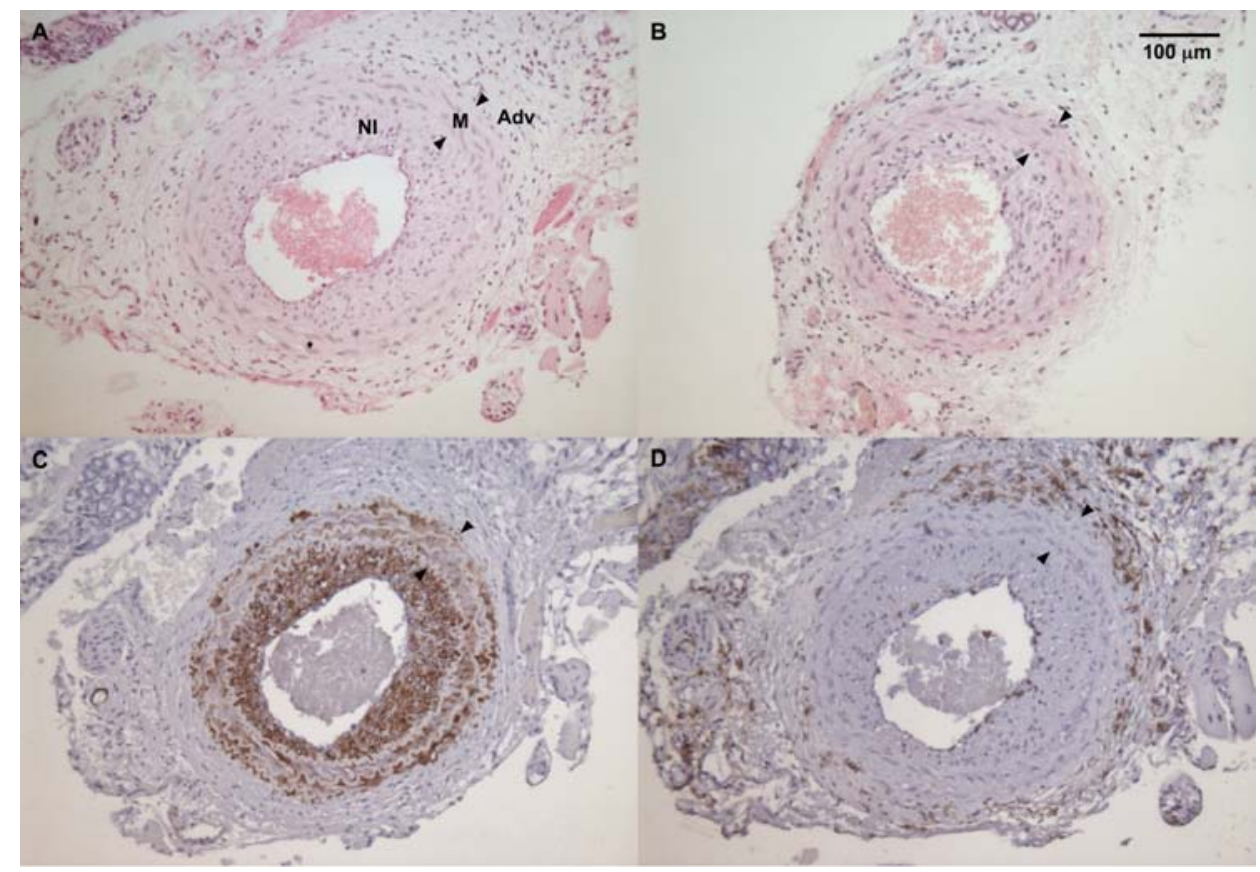

Fig. (3). The average maximum I/M ratio in WT male mice (panel A) was significantly higher than in $\mathrm{sGC \alpha} 1^{-/-}$male mice (panel $\mathbf{B}$ ). The neointima (NI) was almost exclusively composed of SMC actin positive cells (panel C), while almost no CD45-positive cells (panel D) could be detected in the neointima or the media (M) between the internal and external elastic laminae (arrowheads, panel D). CD45 immunoreactivity was predominantly observed in the adventitia (A).

A

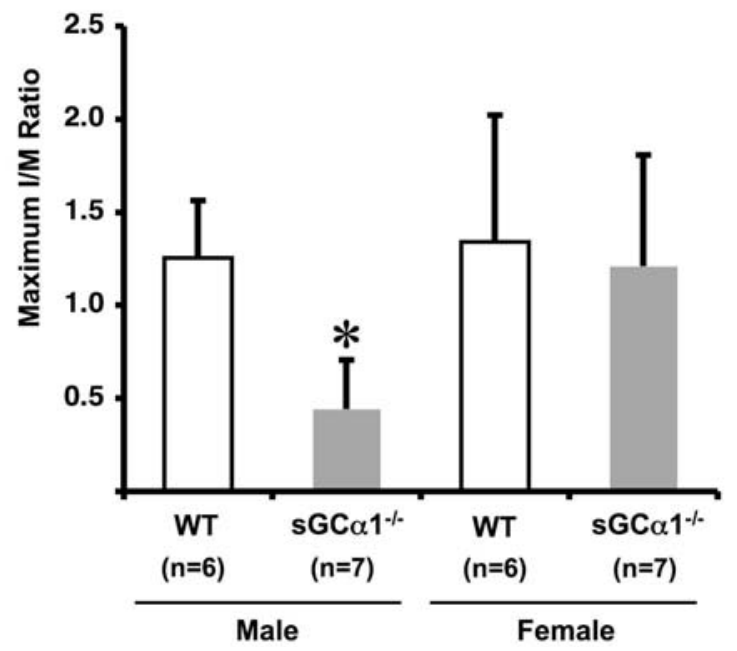

B

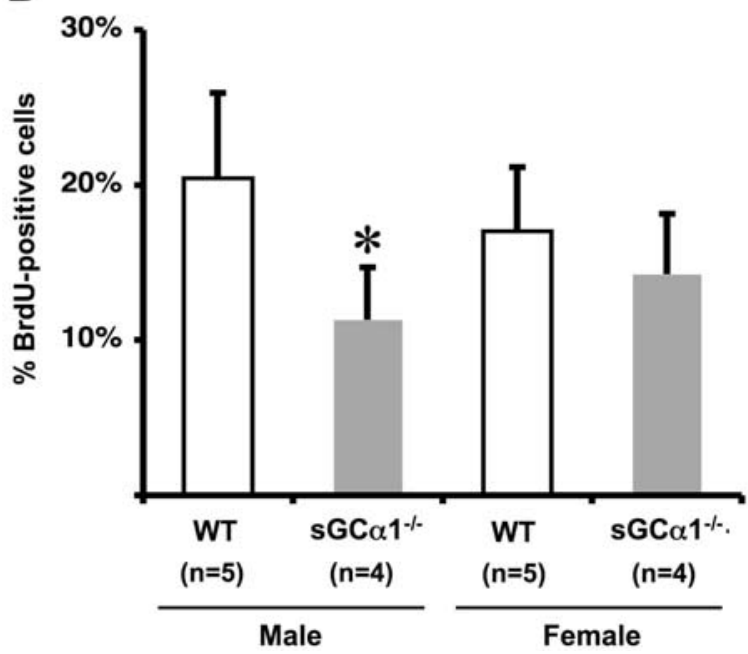

Fig. (4). Maximum I/M ratio 28 days after ligation was reduced in $s G C \alpha 1^{-/-} \mathrm{M}$ compared to WT $\mathrm{M}$ mice and $\mathrm{F}$ mice of either genotype (* $p<0.05$ vs. all, panel A). Proliferation 5 days after ligation, expressed as \% BrdU-positive cells/total number of cells, was also significantly lower in $\mathrm{sGC} \alpha 1^{-/-} \mathrm{M}$ than in WT M mice (* $p<0.05$ vs. WT M mice, panel B), while there was no difference in F mice. 
Table 2. Response to Vascular Injury in WT and sGC $\alpha 1^{-/-}$Mice

\begin{tabular}{|c|c|c|c|c|c|}
\hline & & WT M & 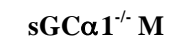 & WT F & $\mathbf{S G C a} \mathbf{1}^{-/} \mathbf{F}$ \\
\hline & Animals & $\mathrm{n}=6$ & $\mathrm{n}=7$ & $\mathrm{n}=6$ & $\mathrm{n}=7$ \\
\hline \multirow[t]{3}{*}{ RCA } & Neointima area $\left(\mu \mathbf{m}^{2}\right)$ & $42,900 \pm 10,300$ & $16,500 \pm 9,900^{*}$ & $36,600 \pm 21,900$ & $43,400 \pm 21,600$ \\
\hline & I/M ratio & $1.25 \pm 0.31$ & $0.44 \pm 0.26^{*}$ & $1.31 \pm 0.72$ & $1.21 \pm 0.60$ \\
\hline & $\%$ Stenosis & $72 \% \pm 19 \%$ & $45 \% \pm 31 \% *$ & $68 \% \pm 32 \%$ & $61 \% \pm 32 \%$ \\
\hline \multirow[t]{2}{*}{ LCA } & IEL length $(\mu \mathrm{m})$ & $1,056 \pm 170$ & $984 \pm 126$ & $1,066 \pm 110$ & $998 \pm 117$ \\
\hline & Media area $\left(\mu \mathbf{m}^{2}\right)$ & $28,700 \pm 6,400$ & $27,800 \pm 3,400$ & $22,500 \pm 5,900$ & $21,700 \pm 2,900$ \\
\hline
\end{tabular}

RCA: injured right carotid artery; LCA: uninjured left carotid artery; IEL: internal elastic lamina; $* p<0.05$ vs. all

study, a targeted deletion in the sGC $\alpha 1$ subunit resulting in a non-functional $\alpha 1 \beta 1$ heterodimer, was associated with a reduced response to vascular injury in male but not in female $\mathrm{sGC} \mathrm{1}^{-/-}$mice compared to WT mice. Male $\mathrm{sGC} \alpha 1^{-1-}$ mice showed a significant reduction in DNA turnover in the remodeling arterial segment 5 days after carotid artery ligation compared to male WT mice and a smaller neointimal area 28 days after ligation. No differences were observed between female $\mathrm{sGC} \mathrm{1}^{-/}$and WT mice. These data suggest an important gender-specific effect of endogenous sGC gene function on the response to systemic vascular injury.

To investigate the effect of reduced sGC gene function on baseline NO/cGMP signal transduction in the vessel wall, we determined aortic cGMP concentrations in male and female WT and $\mathrm{sGC} \mathrm{1}^{-/-}$mice. Aortic cGMP levels were significantly lower in sGC $\alpha 1^{-/-} \mathrm{M}$ than in $\mathrm{sGC} \alpha 1^{-/-} \mathrm{F}$ and $\mathrm{WT}$ $\mathrm{F}$ mice and accompanied by a reduced response to arterial injury. In contrast, higher cGMP levels in WT F mice compared to WT M mice did not translate into a difference in the response to injury, suggesting a threshold cGMP level beyond which the vascular phenotype is no longer affected. Of note, these gender-specific differences were not observed in isolated aortic rings in a recent study by Nimmegeers et al. [16]. This is most likely due to the equilibration of aortic rings in an organ bath for 30 minutes before cGMP concentrations were measured in Nimmegeers et al. [16], while aortas in our study were immediately snap frozen. The gender-specific difference in cGMP levels we observed is consistent with previous observations of increased NO production in female rat aortas [17]. Moreover, the relative role of NO in acetylcholine-mediated vasorelaxation was more pronounced both in Wistar-Kyoto and spontaneously hypertensive female rats [18]. Deletion of $\mathrm{sGC} \alpha 1$ is also associated with a gender-specific effect on systemic blood pressure. Buys et al. recently reported that the deletion of sGCal results in systemic hypertension in male $\mathrm{sGC} \alpha 1^{-/}$ mice but not in female sGC $1^{-/-}$mice [13]. Taken together, these results point to a complex interplay between NO, sGC gene function and gender.

The reduced NO/cGMP signal transduction in $\mathrm{sGC} \alpha 1^{-/-}$ mice did not result in altered mRNA transcript levels of the
sGC subunits. Similarly, increased aortic cGMP levels in transgenic mice overexpressing NOS3 in the vascular endothelium did not affect sGC $\beta 1$ protein expression $[19,20]$. These observations demonstrate that the expression of sGC subunits in the aorta is not modulated via a NO or cGMPmediated feedback mechanism. In contrast, previous in vitro studies reported reduced $\mathrm{sGC} \alpha 1$ mRNA stability and protein expression in cultured SMC following the administration of an NO-donor [21] or a sGC activator [22], underlining the difficulty of extrapolating in vitro observations in cultured $\mathrm{SMC}$ to in vivo NO/cGMP signaling in the vessel wall.

Vascular injury results in reduced NO/cGMP signal transduction in the vessel wall [5]. Strategies aimed at increasing NOS3 expression [4] or reducing NOS uncoupling by administration of L-arginine have successfully reduced neointima formation in rats [23]. The role of endogenous NO-mediated signaling in the adaptive response to injury and the control of vascular SMC proliferation on the other hand remains unclear. The analysis of transgenic mice has shown that NO can both promote and inhibit vascular remodeling [12]. The opposing effects of NO most likely depend on the spatiotemporal profile of NO-production (including cellular source and quantity) and are probably mediated by different cGMP-dependent and cGMPindependent mechanism [24].

Wolfsgruber and colleagues showed that activation of cGKI in vitro promotes vascular SMC growth and that cGKI is critically involved in the ingrowth of SMC in vascular lesions during atherogenesis in an $\mathrm{ApoE}^{-/-}$background [11]. Doubly deficient $\mathrm{ApoE}^{-/-} \mathrm{SMC}^{-\mathrm{CGKI}^{-/-}}$had significantly smaller vascular lesions than $\mathrm{ApoE}^{-/-}$mice. These results suggest that endogenous NO/cGMP/cGKI signaling stimulates rather than inhibits vascular SMC proliferation and that the anti-proliferative effects are mediated by cGMPindependent effects or cGMP-dependent cGKI-independent effects [12]. Stimulation of vascular SMC proliferation is potentially beneficial in atherosclerosis as SMC ingrowth could increase plaque stability and reduce the risk of an atherothrombotic event following plaque rupture. In our study, we observed a reduced response to vascular injury in $\mathrm{sGC} \mathrm{1}^{-/-} \mathrm{M}$ mice compared to WT $\mathrm{M}$ mice. Male $\mathrm{NOS}^{-/-}$ 
mice, in contrast, show increased neointima formation after carotid artery ligation [7]. The systemic hypertension in male

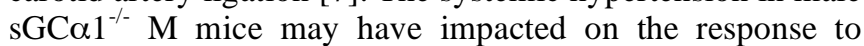
vascular injury. Hypertensive Male $\mathrm{NOS}^{-/-}$mice do, however, show an increased response to vascular injury, while neointima formation is reduced in male ${\mathrm{sGC} \alpha 1^{-1-}}^{-1}$ mice. Taken together, these results support the view that endogenous $\mathrm{NO} / \mathrm{cGMP} / \mathrm{cGKI}$ signaling stimulates rather than inhibits vascular SMC proliferation and indicates that the antiproliferative effect of NO is most likely mediated via cGMP-independent pathways such as direct S-nitrosation of proteins or the formation of peroxynitrite [25].

Studies in transgenic mice have also demonstrated that gender and pregnancy can affect the response to mechanical vascular injury. Male gender enhances the neointima formation in $\mathrm{NOS}^{-/-}$mice after femoral cuff placement, while pregnancy almost completely abolished the intimal response to vascular injury [6]. After femoral cuff placement, the neointima is almost exclusively composed of SMC as is the case after carotid artery ligation (Fig. 3C) [26]. Our results indicate that sGC could play a role in mediating genderspecific effects on the response to vascular injury. Further research is, however, warranted to better characterize the underlying molecular mechanisms. It remains to be determined whether the gender-specific effect of the functional deletion of the sGCa1 subunit on the response to vascular injury is testosterone-dependent as shown for systemic blood pressure [13]. Orchidectomy and treatment with an androgen receptor antagonist prevented hypertension in male sGC $\alpha 1^{-1-}$ mice, while ovariectomy did not influence systemic blood pressure in female mice. Moreover, chronic testosterone treatment increased blood pressure in ovariectomized $\mathrm{sGC} \alpha 1^{-/}$mice, confirming that the effect of sGC on systemic blood pressure was testosterone-dependent.

The carotid artery ligation model used in this study has different characteristics than traditional injury models including wire injury. A study in $\mathrm{ApoE}^{-/-}$mice after bone marrow transplant with GFP and LacZ-positive bone marrow cells showed that there was little contribution of bonemarrow derived cells in the carotid artery ligation model compared to wire injury [26]. This model is therefore not fully representative of endovascular injury in patients. Our study on the other hand allows a relatively specific assessment of the effects of reduced NO/cGMP signal transduction on vascular SMC function after vascular injury without endothelial denudation with only limited interference from of other cell types invading from the circulation (Figs. 3C and 2D). Studying the effect on SMC proliferation is of particular interest for the prevention of in-stent stenosis. While stenting prevents elastic recoil and in-stent restenosis, it is associated with increased SMC proliferation and migration [27]. Further research will be needed to improve our knowledge of NO-mediated cGMP-dependent and cGMP-independent mechanisms in the response to vascular injury to determine whether pharmacologic modulation of NO/cGMP signal transduction could be used to limit restenosis following PCI and to favor optimal healing of stented segments.

In summary, functional deletion of the sGC $\alpha 1$ subunit gene resulted in an impaired response to carotid artery ligation in male $\mathrm{sGC}^{-1-}$ mice but not in female $\mathrm{sGC} \alpha 1^{-1-}$ mice compared to WT mice. The targeted deletion of sGC $\alpha 1$ elicits an important gender-specific effect on the response to vascular injury and may impact on future innovative therapies for arterial injury.

\section{ACKNOWLEDGEMENTS}

This work was supported by a grant of the Fund for Scientific Research-Flanders (to S.J.) and National Heart, Lung, and Blood Institute Grant HL70896 (to K.D.B.). P.V. was a research assistant of the Fund for Scientific ResearchFlanders. S.J. is a Clinical Investigator of the Fund for Scientific Research-Flanders and holder of a chair supported by Astra-Zeneca.

$\begin{array}{ll}\text { ABBREVIATIONS } \\ \text { ApoE } & =\text { Apolipoprotein E } \\ \mathrm{BCA} & =\text { Bicinchoninic acid } \\ \mathrm{BrdU} & =5 \text {-bromo-deoxyuridine } \\ \mathrm{cGK} & =\text { cGMP-dependent protein kinase } \\ \mathrm{cGMP} & =\text { Cyclic guanosine monophosphate } \\ \mathrm{DMEM} & =\text { Dulbecco's modified eagle medium } \\ \mathrm{GTP} & =\text { Guanosine triphosphate } \\ \mathrm{HPRT} & =\text { Hypoxanthine-guanine phosphoribosyltrans- } \\ \mathrm{IEL} & =\text { Internal elastic lamina } \\ \mathrm{I} / \mathrm{M} \text { ratio } & =\text { Intima-to-media ratio } \\ \mathrm{IP} & =\text { Intraperitoneal administration } \\ \mathrm{mRNA} & =\text { Messenger ribonucleic acid } \\ \mathrm{NI} & =\text { Neointima } \\ \mathrm{NO} & =\text { Nitric oxide } \\ \mathrm{NOS} & =\text { Nitric oxide synthase } \\ \mathrm{qPCR} & =\text { Quantitative polymerase chain reaction } \\ \mathrm{SGC} & =\text { Soluble guanylate cyclase } \\ \mathrm{SMC} & =\text { Smooth muscle cell } \\ \mathrm{WT} & =\text { Wild type }\end{array}$

\section{REFERENCES}

[1] Mergia E, Friebe A, Dangel O, Russwurm M, Koesling D. Spare guanylyl cyclase NO receptors ensure high NO sensitivity in the vascular system. J Clin Invest 2006; 116: 1731-9.

[2] d'Uscio LV, Baker TA, Mantilla CB, et al. Mechanism of endothelial dysfunction in apolipoprotein E-deficient mice. Arterioscler Thromb Vasc Biol 2001; 21: 1017-22.

[3] Varenne O, Pislaru S, Gillijns H, et al. Local adenovirus-mediated transfer of human endothelial nitric oxide synthase reduces luminal narrowing after coronary angioplasty in pigs. Circulation 1998; 98 : 919-26.

[4] Janssens S, Flaherty D, Nong Z, et al. Human endothelial nitric oxide synthase gene transfer inhibits vascular smooth muscle cell proliferation and neointima formation after balloon injury in rats. Circulation 1998; 97: 1274-81.

[5] Sinnaeve P, Chiche JD, Nong Z, et al. Soluble guanylate cyclase alpha(1) and beta(1) gene transfer increases NO responsiveness and reduces neointima formation after balloon injury in rats via antiproliferative and antimigratory effects. Circ Res 2001; 88: 1039. 
[6] Moroi M, Zhang L, Yasuda $\mathrm{T}$, et al. Interaction of genetic deficiency of endothelial nitric oxide, gender, and pregnancy in vascular response to injury in mice. J Clin Invest 1998; 101: 122532.

[7] Zhang LN, Wilson DW, da Cunha V, et al. Endothelial NO synthase deficiency promotes smooth muscle progenitor cells in association with upregulation of stromal cell-derived factor-1alpha in a mouse model of carotid artery ligation. Arterioscler Thromb Vasc Biol 2006; 26: 765-72.

[8] Knowles JW, Reddick RL, Jennette JC, Shesely EG, Smithies O, Maeda N. Enhanced atherosclerosis and kidney dysfunction in eNOS(-/-)Apoe(-/-) mice are ameliorated by enalapril treatment. J Clin Invest 2000; 105: 451-8.

[9] Kuhlencordt PJ, Gyurko R, Han F, et al. Accelerated atherosclerosis, aortic aneurysm formation, and ischemic heart disease in apolipoprotein E/endothelial nitric oxide synthase double-knockout mice. Circulation 2001; 104: 448-54.

[10] Ozaki M, Kawashima S, Hirase T, et al. Overexpression of endothelial nitric oxide synthase in endothelial cells is protective against ischemia-reperfusion injury in mouse skeletal muscle. Am J Pathol 2002; 160: 1335-44.

[11] Wolfsgruber W, Feil S, Brummer S, Kuppinger O, Hofmann F, Feil R. A proatherogenic role for cGMP-dependent protein kinase in vascular smooth muscle cells. Proc Natl Acad Sci USA 2003; 100: 13519-24.

[12] Feil R, Feil S, Hofmann F. A heretical view on the role of NO and cGMP in vascular proliferative diseases. Trends Mol Med 2005; 11: 71-5.

[13] Buys ES, Sips P, Vermeersch P, et al. Gender-specific hypertension and responsiveness to nitric oxide in sGCalphal knockout mice. Cardiovasc Res 2008; 79: 179-86.

[14] Vermeersch P, Buys E, Pokreisz P, et al. Soluble guanylate cyclase-alpha1 deficiency selectively inhibits the pulmonary vasodilator response to nitric oxide and increases the pulmonary vascular remodeling response to chronic hypoxia. Circulation 2007; 116: 936-43.

[15] Kumar A, Lindner V. Remodeling with neointima formation in the mouse carotid artery after cessation of blood flow. Arterioscler Thromb Vasc Biol 1997; 17: 2238-44.
[16] Nimmegeers S, Sips P, Buys E, Brouckaert P, Van de Voorde J. Functional role of the soluble guanylyl cyclase alpha(1) subunit in vascular smooth muscle relaxation. Cardiovasc Res 2007; 76: 149 59.

[17] Kauser K, Rubanyi GM. Gender difference in bioassayable endothelium-derived nitric oxide from isolated rat aortae. Am J Physiol 1994; 267: H2311-7.

[18] Kahonen M, Tolvanen JP, Sallinen K, Wu X, Porsti I. Influence of gender on control of arterial tone in experimental hypertension. Am J Physiol 1998; 275: H15-22.

[19] Ohashi Y, Kawashima S, Hirata K, et al. Hypotension and reduced nitric oxide-elicited vasorelaxation in transgenic mice overexpressing endothelial nitric oxide synthase. J Clin Invest 1998; 102: 2061-71.

[20] Yamashita T, Kawashima S, Ohashi Y, et al. Mechanisms of reduced nitric oxide/cGMP-mediated vasorelaxation in transgenic mice overexpressing endothelial nitric oxide synthase. Hypertension 2000; 36: 97-102.

[21] Filippov G, Bloch DB, Bloch KD. Nitric oxide decreases stability of mRNAs encoding soluble guanylate cyclase subunits in rat pulmonary artery smooth muscle cells. J Clin Invest 1997; 100: 942-8.

[22] Kloss S, Furneaux H, Mulsch A. Post-transcriptional regulation of soluble guanylyl cyclase expression in rat aorta. J Biol Chem 2003; 278: 2377-83.

[23] Vermeersch P, Nong Z, Stabile E, et al. L-arginine administration reduces neointima formation after stent injury in rats by a nitric oxide-mediated mechanism. Arterioscler Thromb Vasc Biol 2001; 21: $1604-9$.

[24] Hofmann F, Feil R, Kleppisch T, Schlossmann J. Function of cGMP-dependent protein kinases as revealed by gene deletion. Physiol Rev 2006; 86: 1-23.

[25] Walford G, Loscalzo J. Nitric oxide in vascular biology. J Thromb Haemost 2003; 1: 2112-8.

[26] Tanaka K, Sata M, Hirata Y, Nagai R. Diverse contribution of bone marrow cells to neointimal hyperplasia after mechanical vascular injuries. Circ Res 2003; 93: 783-90.

[27] Serruys PW, Kutryk MJ, Ong AT. Coronary-artery stents. N Engl J Med 2006; 354: 483-95.

(C) Vermeersch et al.; Licensee Bentham Open.

This is an open access article licensed under the terms of the Creative Commons Attribution Non-Commercial License (http://creativecommons.org/licenses/by$\mathrm{nc} / 3.0 /$ ) which permits unrestricted, non-commercial use, distribution and reproduction in any medium, provided the work is properly cited. 